World Scientific Series in Computer Science - Vol. 27

\title{
ADVANCES IN ARTIFICIAL INTELLIGENCE APPLICATIONS and THEORY
}

Editor

James C. Bezdek

Division of Computer Science

University of West Florida

Pensacola, Florida 


\section{Published by}

World Scientific Publishing Co. Pte. Ltd.

P O Box 128, Farrer Road, Singapore 9128

USA office: 687 Hartwell Street, Teaneck, NJ 07666

UK office: 73 Lynton Mead, Totteridge, London N20 8DH

\section{ADVANCES IN ARTIFICIAL INTELLIGENCE - APPLICATIONS AND THEORY}

Copyright $\odot 1990$ by World Scientific Publishing Co. Pte. Ltd.

All rights reserved. This book, or parts thereof, may not be reproduced in any form or by any means, electronic or mechanical, including photocopying, recording or any information storage and retrieval system now known or to be invented, without written permission from the Publisher.

ISBN $981-02-0525-2$

Printed in Singapore by JBW Printers and Binders Pte. Ltd. 
This note introduces you to our special issue consisting of papers which are, in the main, extensions of preliminary work reported in the Proceedings of the 1989 SPIE Symposium-Applications of Artificial Intelligence VII, edited by Mohan Trivedi.

I chose six papers each in the applications and theory areas. The applications papers were chosen because each discusses a system that is (or is close to being) a fielded system that solves real problems using one or more AI techniques. The six theory papers included in this issue were selected as representatives of recent advances in various theoretical aspects of $\mathrm{AI}$ technology; that is, these articles concern themselves with one or more components of next generation AI systems. My overall plan for the issue was to strike a genuine balance between applications and theory; and I believe the contents of this issue reflect that objective.

Rather than provide a detailed synopsis of the twelve papers, I will be content to indicate their general scope. In the applications group, the set of articles describes the use of expert systems in six richly varied problem domains: computer-aided education, hydrocarbon (oil) exploration, satellite image analysis for oceanography, particle beam accelerator tuning, assessment of predilection to bleeding in tonsillectomy patients, and the design of internal combustion engines. Note especially the general areas covered by these contributions: education, energy, physics, control, medicine, and mechanical engineering. This breadth seems to corroborate early beliefs that AI-based technologies will eventually provide a means for representing and solving difficult problems in every domain dominated by human experts.

Papers in the theory group cover a wide spectrum of more basic issues. These papers are devoted to topics that I call "building-block" issues; theories, algorithms, architectures, and software tools that can or will be used for modules within future systems. Areas included in this group: conceptual clustering for non-numerical data, natural language interfaces to object-oriented databases, adaptive planning for air combat maneuvers, a distributed problem-solving paradigm for cooperative computation, and two papers about AI tools-CAUSA for knowledge acquisition, and PRIOPS for knowledge-based system programming. As in the applications group, this set of papers covers a nice range of topics related to theoretical issues in $\mathrm{AI}$ : clustering, natural language, adaptive algorithms, distributed processing, knowledge acquisition, and systems programming.

Collectively, then, this issue amounts to a sampler that illustrates: (i) that AI theory continues to advance, just as applications in many domains are beginning to mature; and (ii) the varied and various nature of the aforementioned SPIE conference, which is held annually in Orlando, Florida, USA. The papers were carefully selected, all being first rate, and should satisfy the appetite of almost all readers. I enjoyed preparing the special issue; I certainly encourage you to enjoy reading it. 
This page is intentionally left blank 


\section{CONTENTS}

Preface

iii

J. C. Bezdek

An Intelligent Image-Based Computer-Aided Education System:

The Prototype BIRDS

A. A. David, O. Thiery \& M. Crehange

PLAYMAKER: A Knowledge-Based Approach to Characterizing Hydrocarbon Plays

G. Biswas, X. Yu, W. Hagins, J. Bezdek, J. Strobel,

C. Kendall \& R. Cannon

An Expert System for Interpreting Mesoscale Features

in Oceanographic Satellite Images

$N$. Krishnakumar, S. S. Iyengar, R. Holyer \& M. Lybanon

An Expert System for Tuning Particle Beam Accelerators

D. L. Lager, H. R. Brand \& W. J. Maurer

Expert System Approach to Assessments of Bleeding

Predispositions in Tonsillectomy/Adenoidectomy Patients

N. J. Pizzi \& J. M. Gerrard

Expert System Approach Using Graph Representation and Analysis for Variable-Stroke Internal-Combustion Engine Design

S. N. T. Shen, M.-S. Chew \& G. F. Issa

A Comparison of Two New Techniques for Conceptual Clustering

S. L. Crawford \& S. K. Souders

Querying an Object-Oriented Database Using Free Language

P. Trigano, J.-P. Barthes, C. Greboval \& F. Vallernaud

Adaptive Planning for Air Combat Maneuvering

I. C. Hayslip, J. P. Rosenking \& J. Eilbert

AM/AG Model: A Hierarchical Social System Metaphor for Distributed Problem Solving

D. G. Shin \& J. Leone 
CAUSA-A Tool for Model-Based Knowledge Acquisition W. Dilger \& J. Möller

PRIOPS: A Real-Time Production System Architecture for Programming and Learning in Embedded Systems

D. E. Parson \& G. D. Blank 